\title{
O POETA, A CRENTE E O BERRANTE: OFICINAS DE TEATRO NO PROJETO RONDON EM SÃO BENEDITO DO RIO PRETO-MA
}

Taís Ferreira ${ }^{1}$

RESUMO: Este relato de experiência visa comentar os encontros entre a professora coordenadora das oficinas de teatro, planejadas e realizadas no âmbito do Projeto Rondon, Operação Catirina, no município de São Benedito do Rio Preto, Maranhão, em julho de 2010, e mais de 100 jovens (dos quais três deles especialmente referidos), em espaços-tempo formativos, nos quais se entrelaçam a construção de identidades e de sensibilidades.

PALAVRAS-CHAVE: Oficinas de teatro. Jovens. Projeto Rondon.

The poet, the devout and the blowing horn: theater workshops in the Rondon project in São Benedito do Rio Preto, Maranhão State, Brazil

\begin{abstract}
This experience report discusses the meetings between the tutor teacher of theater workshops and more than 100 young people (of which three of them are specifically mentioned). The workshops were planned and carried out through the "Rondon Project, Catirina Operation" (Projeto Rondon, Operação Catirina), in formative spaces and times, in which the construction of identities and sensibilities intertwine. They were held in São Benedito do Rio Preto, Maranhão state, July, 2010.
\end{abstract}

KEYWORDS: Theater workshops. Young people. Rondon Project.

\section{INTRODUÇÃO}

Todos nós (ou quase todos), aos treze ou quatorze anos de idade, achamos que temos alguma ingerência sobre o mundo que nos cerca e que podemos transformá-lo a partir de nossas ações e vontades. Alguns poucos anos vividos nos mostram a ingenuidade destes pensamentos e, frequentemente, nos deixamos tomar pela apatia: o mundo não vai mudar mesmo, de que me adianta sofrer pelos outros? Vou pensar em mim, construir minha vida, minha carreira, minhas relações, ter um hobby como jogar vôlei ou praticar yoga e esquecer das mazelas dos homens, dos animais, dos vegetais e do mundo. Na minha torneira tem água, na padaria tem pão, a internet está funcionando e é isso o que importa. Claro, sempre é bom que a gasolina não esteja tão cara também...

Este é o percurso existencial que atravessa a constituição identitária de boa parte dos jovens de classe média hoje no Brasil. Comigo não foi diferente. Ainda sou jovem, uma jovem professora, mas agora que entro na plena vida adulta, percebo que os últimos dez anos de minha vida (este é o tempo em que me formei, ingressei no mercado de trabalho e constituí-me como não adolescente, ou seja, adulta, com plenas responsabilidades e com os fardos e as obrigações da vida adulta)

\footnotetext{
${ }^{1}$ Mestre em Educação pela Universidade Federal do Rio Grande do Sul, professora do Núcleo de Artes Cênicas do Centro de Artes da Universidade Federal de Pelotas (taisferreirars@yahoo.com.br). 
guardaram uma centelha daquela vontade da menina de quatorze anos que chorava pelos cantos da casa porque a mãe não a deixou atravessar o Brasil de ônibus para participar do Congresso da UNE (União Nacional dos Estudantes) e da rapariga falante que, aos doze anos, participou do "Fora Collor" e foi uma "cara-pintada" e, ainda que o movimento tenha se tornado uma espécie de alegoria da década de1990, o sentimento de muitos dos jovens ali, como o meu, foi verdadeiro e repercutiu em nossas posições éticas e políticas perante a vida, as coisas e os homens.

O ano de 2010 fez-me retomar uma série destas crenças adolescentes e pré-adolescentes, com as quais agora estou empenhada, não mais na busca vã de salvar o mundo, mas na tentativa esforçada de alcançar e atravessar, por meio de minhas ações, alguns mundos - pequenos mundos - como o mundo do poeta, o mundo da crente e o mundo do tocador de berrante, sobre os quais se sustenta este relato.

\section{O Poeta}

Estávamos na cidade de São Benedito do Rio Preto-MA, trabalhando já há uma semana, todas as noites, com um enorme grupo de jovens da cidade, em uma oficina de teatro, eu, uma aluna da Universidade Federal de Pelotas (UFPel) e um aluno da Universidade de Taubaté (UNITAU)². Tudo corria bem, jovens contentes, corpos vivos, disposição e alegria. Eram quase noventa jovens e, depois de uma semana, já podíamos distinguir aqueles mais interessados e esforçados dos que ali estavam para se divertir e conviver (função legítima também esta, de uma oficina livre de teatro).

No entanto, o poeta mostrava-se, desde o início, atento e compenetrado em todos os jogos e exercícios propostos. Com o passar dos dias, nas conversas de início e final de aula, descobrimos que o rapaz de 23 anos morava e trabalhava na zona rural com a mãe e suas irmãs mais novas, que seu pai havia morrido há poucos meses, que ele andava (pasmem!) 45 minutos de bicicleta pela estrada de chão, todos os dias, ida e volta, para estar na oficina. Uma enorme cicatriz cortava a face do jovem moreno e de fala mansa. Ele nos contou que, trabalhando na roça, fora picado no rosto por uma cobra muito venenosa e que ficara um ano internado em um hospital de São Luís, na capital, onde quase morrera.

Por tudo isso o jovem já seria motivo de muita admiração, não fosse ele me surpreender em um final de aula com a seguinte pergunta: "Professora, para ter teatro precisa ter texto?". Respondo que não, que da mesma forma que trabalhávamos na oficina com improvisações, eles também poderiam criar a partir daquilo que tivessem vontade. "Ah, é que eu escrevo, eu sou poeta", respondeu-me acanhadamente, estendendo-me uma folha de caderno dobrada várias vezes e dizendo: "Quer ler, professora? Eu fiz para o meu pai que morreu...".

Peguei a folha, levei para casa, li. No outro dia, pedi uma cópia, que o poeta me entregou na outra aula, passada a limpo a caneta, de próprio punho. Ele disse-me que queria ser escritor, que sonhava em cursar Letras. Em nosso último dia na cidade, o poeta nos trouxe uma carta, que ele mesmo escrevera e queria ler antes da apresentação, na qual nos agradecia e falava da importância que a oficina teve para aqueles jovens e da sua vontade de dar continuidade ao trabalho. Tudo lento, tudo manso, como ele, o jovem poeta que sobreviveu à cobra e agora podia sonhar e escrever poesia.

\footnotetext{
${ }^{2}$ Os rondonistas referidos são, respectivamente, Lucia Elaine Berndt e Jardel Narezi. 


\section{A Crente}

A gorduchinha baixinha chegou rindo: cochichando pelos cantos e soltando risinhos tímidos. De saia. Assim foi a primeira aula, ela de saia, rindo e cochichando. No segundo dia, ela para do meu lado e pergunta: “Tô bonita, professora?". Eu olho para ela, não vejo nada de novo e respondo que sim. "Ai, professora, é que é a primeira vez que eu saio de casa de bermuda!". A menina era de uma religião evangélica que não permite às mulheres usarem calças e bermudas, somente saias.

E a gorduchinha abre um sorriso largo, emoldurado pelas molinhas do cabelo cacheado bem arrumadinho. Pequenas ações que representam desprendimento e vontade de participar, mesmo que tendo que abrir mão de algumas convicções religiosas. E a baixinha de sorriso largo e riso fácil tornou-se minha amiga: além de participar da oficina de teatro todas as noites, cursou toda a oficina de confecção de fantoches de papel machê, ministrada por mim no período da manhã. Rimos muito juntas. Ela me contou do seu "noivo secreto", perguntou sobre como era "aqui no Sul", se eu era casada, se tinha filhos e, por várias vezes, repetiu a frase que mais me fez rir naqueles dias de São Benedito: "Ai, professora, o que que a senhora acha? Eu sou crente, mas eu sou feliz! Eu gosto mesmo é de dançar e rebolar!”.

E nos divertimos juntas, entre "rebolations" tocados no rádio e histórias contadas, entre papel machê e tintas coloridas, porque a baixinha contente "era crente, mas gostava de se divertir". $\mathrm{E}$, assim, vemos nossos preconceitos aos poucos serem desconstruídos pelas pessoas, por suas ações, suas falas, suas intenções. Construímos, no lugar deles, uma nova visão do nosso próprio mundo e do modo como lidamos com as pessoas e com as situações que vivenciamos.

\section{O berrante}

O berrante (instrumento típico dos vaqueiros da região), aqui tratado, esteve durante parte da oficina de teatro nos braços de um dos alunos mais eficientes e dedicados que já tive e simboliza o belo trabalho que a equipe do teatro realizou na Operação Catirina, durante o Projeto Rondon 2010. Durante duas semanas, todas as noites, jovens entre 11 e 25 anos estiveram conosco, brincando e fazendo teatro, com seus corpos agindo e colocando-se, criando e experienciando vivências até então inéditas em suas histórias, contando-nos sobre suas vidas e realidades, trocando conosco e se apropriando avidamente de tudo aquilo que apresentávamos a eles, em uma enorme sede de sorver aqueles momentos.

O berrante fez parte de uma apresentação em praça pública, realizada com os noventa alunos e alunas da oficina de teatro em São Benedito do Rio Preto-MA. Por meio de seus corpos, eles contaram suas próprias histórias e brincaram com o imaginário que tinham de um Sul tão longínquo quanto o Rio Grande do Sul, de onde vínhamos, e de um São Paulo, mais próximo geograficamente, mas tão distante deles culturalmente quanto os gaúchos ali presentes.

Praticamente todos os participantes concordaram em participar da apresentação, mesmo tendo que se 
expor abertamenteem praça pública lotada, cumprenotar, com grande parte da população local presente.

Os jovens foram chegando, fulgurantes, de branco (havíamos combinado que todos iriam vestidos com roupas brancas), excitados. A minha "alegre crente", empolgada, cuidava da banca de exposição dos fantoches e queria dublar uma música, que, infelizmente, não houve como inserir na programação, que já era extensa. Nosso "poeta" leu seu texto de agradecimento. E o dedicado Marquinho, que já havia escalado a fachada da igreja, à tarde, para trocar as lâmpadas e preparar tudo para a apresentação da noite, absolutamente engajado em nossa proposta, toca seu berrante. Damos início ao espetáculo. Em vinte minutos, todos nós éramos outros: havíamos aprendido uns com os outros e levávamos um pouco uns dos outros conosco. Fomos atravessados por aquilo que chamamos de experiência: que nos marca, que deixa sulcos em nossos corpos e nossas almas, que nos (trans)forma (LARROSA, 2000).

\section{CONSIDERAÇÕES FINAIS}

Agora, adulta, atravessada que fui pelos olhos brilhantes e pela empolgação daqueles jovens humildes - muitos da roça, muitos trabalhadores braçais, uns evangélicos, alguns assaz católicos, outros com poucas perspectivas em suas vidas, todos com sonhos - sinto-me um pouco novamente aquela que teve treze anos e acreditou na mudança, de forma ingênua, mas que faz nascer dentro da gente uma esperança que traz a vontade de viver, de agir e de se relacionar com a humanidade e o mundo que nos cerca. Essas são lições que aprendemos, sempre, sem que ninguém nos diga que está nos ensinando.

\section{AGRADECIMENTOS}

Agradeço ao poeta, à crente e ao berrante (que simbolizam todos aqueles 90 jovens maranhenses) que me ensinaram a ter, novamente, treze anos.

\section{REFERÊNCIAS}

LARROSA, J. Notas sobre a experiência e o saber de experiência. Tradução de João Wanderley Geraldi. Revista Brasileira de Educação, Rio de Janeiro, v. 19, p. 20-28, jan./abr. 2002.

Submetido em 17 de outubro de 2012.

Aprovado em 7 de janeiro de 2013. 


\section{ANEXOS}

Figura 1 - Jovens na oficina de teatro, conduzidos pelo rondonista (em pé) em exercício de relaxamento e imaginação.

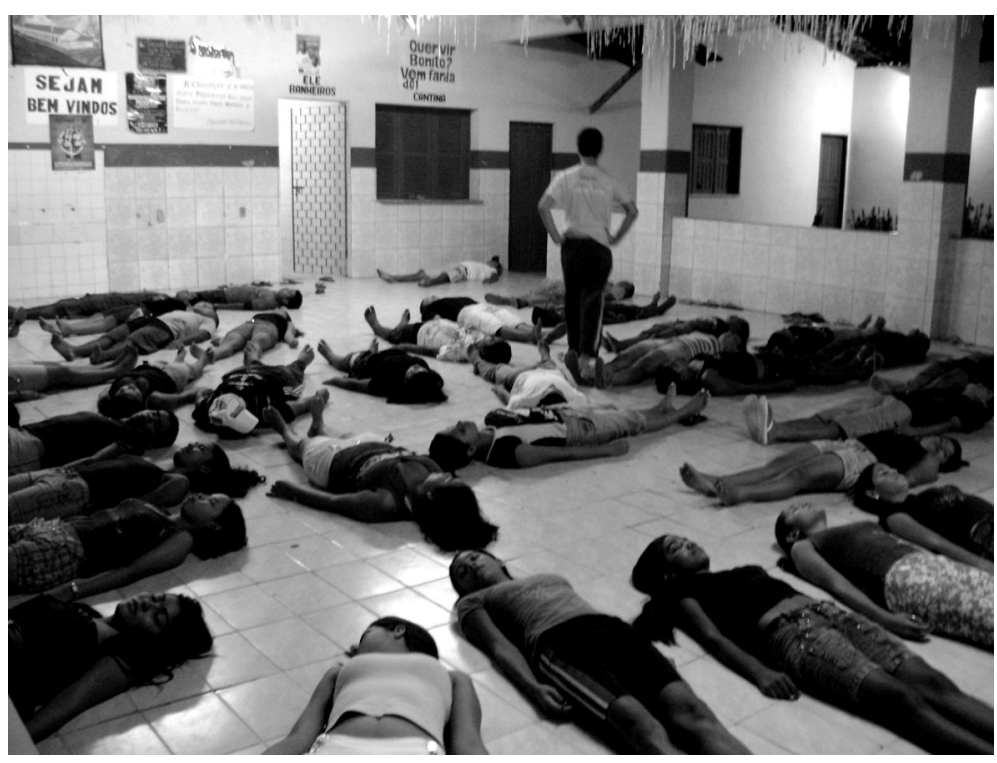

Fonte: Acervo da autora.

Figura 2 - Jovens confeccionando bonecos na oficina de fantoches.

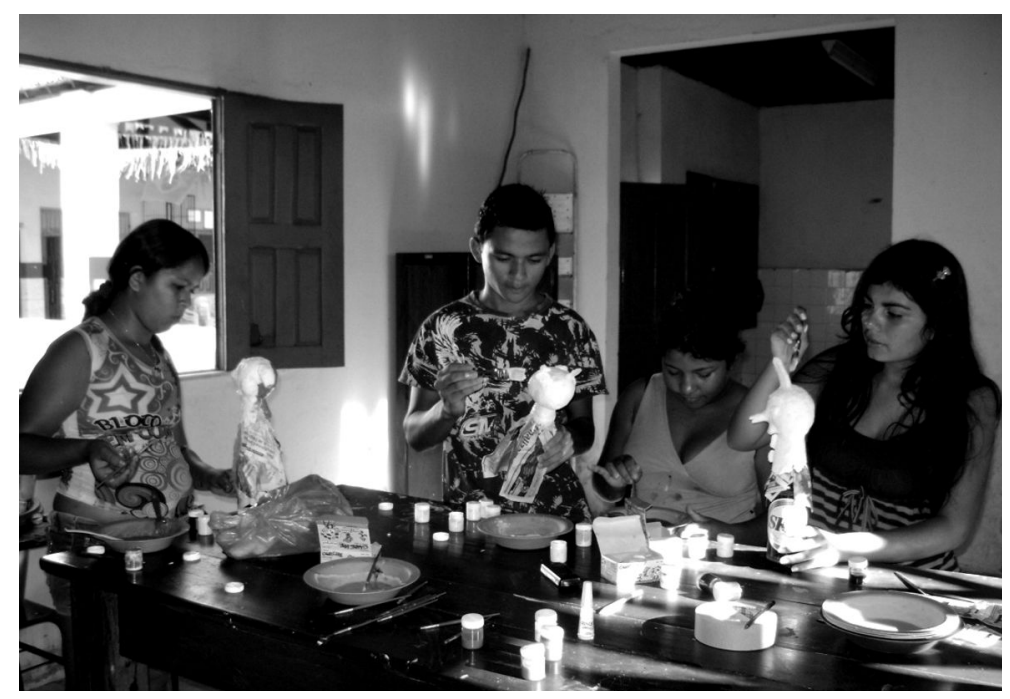

Fonte: Acervo da autora. 